\title{
Desenvolvendo o raciocínio espacial na formação inicial de professores dos primeiros anos
}

\section{Developing spatial reasoning in prospective elementary teacher education}

\author{
Lina Brunheira ${ }^{1}$ \\ João Pedro da Ponte ${ }^{2}$
}

\begin{abstract}
Resumo
Este artigo enquadra-se numa experiência de formação inicial com futuros professores e educadores. O objetivo é compreender de que forma as tarefas exploratórias podem contribuir para o desenvolvimento do raciocínio espacial e quais os processos de raciocínio que promovem. Os dados foram recolhidos por registos áudio e vídeo e a sua análise incidiu nos processos de construção, análise e transformação de modelos mentais e operações com modelos mentais. O estudo sugere que o tipo de tarefas propostas, os recursos e as interações na sala de aula são condições relevantes para a ativação destes processos. No que respeita às tarefas, a realização de contagens de elementos dos poliedros e o estabelecimento de relações e justificações revelam-se promotores dos processos de raciocínio espacial; o material manipulável é importante como suporte, mas a sua utilização deve ser limitada; e o contexto de trabalho colaborativo favorece a comunicação do raciocínio e a estruturação espacial.
\end{abstract}

Palavras-chave: Geometria; Raciocínio Espacial; Poliedros; Formação inicial de professores.

\begin{abstract}
This article reports a research concerning a prospective teacher education experiment. The aim of this study is to understand the contribution of exploratory tasks to the development of spatial reasoning and which are the processes of spatial reasoning promoted. Data was gathered from audio and video records and the analysis focused on the processes of constructing mental models, as well as inspecting, transforming and operating with mental models. The study suggests that the type of tasks, the physical models made available and the interactions in the classroom are relevant conditions to the activation of these processes. In respect to the tasks, the enumeration of elements of the polyhedra and the establishment of relations and justifications promote the processes of spatial reasoning; the physical models are important as a support, but its use should be limited; and the collaborative work context favours the communication of reasoning and the spatial structuring of objects..
\end{abstract}

Keywords: Geometry; Spatial reasoning; Structuring; Prospective Teacher Education.

\section{Introdução}

A evolução da matemática no séc. XIX, onde a busca pelo rigor se traduziu na recusa das demonstrações apoiadas em figuras e na desconfiança sobre a perceção visual, contribuiu

\footnotetext{
Submetido em: 05/07/2018 - Aceito em: 14/10/2018 - Publicado em: 15/10/2018

${ }^{1}$ Doutoranda em Educação, especialidade em Didática da Matemática, no Instituto de Educação, Universidade de Lisboa, Portugal. Professora na Escola Superior de Educação de Lisboa, Portugal. Email: lbrunheira@eselx.ipl.pt

${ }^{2}$ Doutor em Mathematics Education pela University of Georgia, EUA. Professor catedrático do Instituto de Educação, Universidade de Lisboa, Portugal. Email: jpponte@ie.ulisboa.pt
} 
DOI: http://dx.doi.org/10.20396/zet.v26i3.8652882

para a desvalorização do raciocínio espacial ${ }^{3}$ (Veloso, 1998). Também a ausência de investigação na área da visualização, particularmente depois de a psicologia ter sido dominada pela corrente behaviorista, teve uma influência na sua desvalorização (Presmeg, 2006). Contudo, a evolução das perspectivas sobre a geometria que identificamos em matemáticos como Atiyah (1982) ou Malkevitch (2009), valorizando a sua componente visual, contribuíram para uma mudança de paradigma. Também no campo da psicologia e da educação matemática, vários investigadores têm sublinhado a importância do raciocínio espacial. Por exemplo, para Battista (2007), “o raciocínio espacial fornece não apenas o input para o raciocínio geométrico formal, mas também ferramentas cognitivas críticas para uma análise geométrica formal" (p. 844), atribuindo assim um papel decisivo à componente visual, mesmo em situações onde já se opera a um nível mais formal. Da mesma forma, Johnston-Wilder e Mason (2005) referem-se à visualização como sendo uma característica inerente ao raciocínio geométrico, constituindo uma ferramenta poderosa: "Talvez o poder mais importante de todos é o poder de imaginar e expressar o que é imaginado através de gestos, movimentos, diagramas, palavras e símbolos” (p. 131). Por sua vez, Duval (1999) refere a importância da visualização além do campo da geometria na medida em que a "representação e a visualização estão no coração da compreensão matemática" (p. 3).

Sinclair et al. (2016) afirmam que na última década o raciocínio espacial tem merecido uma atenção crescente na investigação, quer no campo da educação matemática, quer das ciências cognitivas e, se é verdade que este tipo de raciocínio é relevante em todas as áreas da matemática, merece sem dúvida um destaque particular no ensino e aprendizagem da geometria. Contudo, estes autores defendem a necessidade de mais investigação sobre a promoção de oportunidades de envolvimento em raciocínio espacial, tanto para alunos como professores, bem como as formas de avaliar e valorizar tal raciocínio. Nesse sentido, este artigo visa compreender de que forma as tarefas podem contribuir para o desenvolvimento do raciocínio espacial e quais os processos de raciocínio envolvidos durante a sua resolução. Concretamente, procuraremos responder às seguintes questões: Quais os processos de raciocínio espacial em que os formandos se envolvem quando resolvem tarefas de contagem e estabelecimento de relações em classes de poliedros? De que forma estas tarefas, realizadas num contexto de ensino exploratório, podem contribuir para o desenvolvimento do raciocínio espacial?

\section{Raciocínio espacial}

$\mathrm{Na}$ recente revisão de estudos feita por Sinclair et al. (2016) a partir de 2008, os autores referem a existência de vários termos ou expressões que pretendem significar algo parecido e que têm em comum a atividade de imaginar objetos estáticos ou dinâmicos e atuar sobre eles (por exemplo, rodar, aumentar, etc.). Já anteriormente, Gutiérrez (1996) referia que a literatura existente sobre visualização até à data inclui uma grande variedade de termos e expressões (entre os quais raciocínio visual, pensamento espacial, imagens mentais, espaciais,

\footnotetext{
${ }^{3}$ Este conceito é também designado por outros investigadores por visualização, raciocínio visual, pensamento espacial e outras designações com significado idêntico (Gutiérrez, 1996; Sinclair et al., 2016).
} 
DOI: http://dx.doi.org/10.20396/zet.v26i3.8652882

visuais, etc.) gerando uma "confusão" que reflete a coexistência de diferentes áreas de investigação que se dedicam ao estudo da visualização, entre elas a educação matemática e a psicologia e, neste último caso, com diferenças entre as abordagens dos psicólogos de educação e os cognitivistas.

Consideremos a proposta de Battista (2007) que define raciocínio espacial como sendo a

capacidade de 'ver', analisar e refletir sobre objetos espaciais, imagens, relações e transformações. O raciocínio espacial inclui gerar imagens, analisá-las para responder a questões sobre elas, transformar e operar sobre imagens, e manter as imagens ao serviço de outras operações mentais. (p. 843)

Pelo seu lado, Gutiérrez (1996) utiliza o termo visualização, mas a sua definição é muito próxima da anterior, pois concebe-a como um tipo de raciocínio baseado no uso de elementos visuais ou espaciais, igualmente desenvolvida com vista à resolução de questões, como problemas ou demonstração de propriedades. Para este investigador, este tipo de raciocínio integra quatro elementos principais: imagens mentais, representações externas, processos de visualização e capacidades de visualização.

As imagens mentais são o centro do raciocínio espacial. Gutiérrez (1996) define imagem mental como um tipo de representação cognitiva de um conceito ou propriedade através de elementos visuais ou espaciais que assume constituir o elemento básico. No entanto, considera relevante ter ainda em conta outro tipo de representações que mobilizamos e se articulam com as imagens mentais: as representações externas, que correspondem a qualquer tipo de representação verbal ou gráfica de conceitos ou propriedades, incluindo retratos, desenhos, diagramas, etc. que ajudam a criar ou transformar as imagens mentais e a realizar raciocínio espacial.

Para o autor, um processo de visualização é uma ação mental ou física que envolve imagens mentais. Existem dois processos: a interpretação visual da informação para criar as imagens mentais e a interpretação de imagens mentais para gerar informação, a qual se decompõe em três subprocessos: observação e análise de imagens mentais, transformação de imagens mentais noutras imagens mentais e a transformação de imagens mentais noutro tipo de informação.

Na perspetiva de Battista (2009), para que seja possível operar mentalmente com objetos geométricos (por exemplo, compará-los, decompô-los e analisá-los), é necessário que estes tenham sido abstraídos a um nível suficientemente profundo, o que envolve a estruturação espacial. A estruturação espacial é um tipo especial de abstração correspondente ao ato mental de construir uma organização ou uma configuração para um objeto ou conjunto de objetos. Inclui identificar unidades, relações entre as unidades e reconhecer que um subconjunto de objetos, devidamente repetidos, pode gerar o conjunto todo (Battista \& Clements, 1996). A estruturação espacial está assim associada a um modelo mental, ou seja, uma versão visual, não-verbal, da situação (objeto, ação...) que tem uma estrutura isomórfica à estrutura percecionada da situação e que é ativada para interpretar e raciocinar sobre ela (Battista, 2007). Por exemplo, diferentes formas de estruturar um quadrilátero determinam modelos diferentes, como um caminho fechado constituído por quatro segmentos, uma composição de segmentos unidos pelos seus extremos ou uma composição de quatro ângulos ligados.

No caso de objetos tridimensionais, a construção de modelos mentais envolve a 
DOI: http://dx.doi.org/10.20396/zet.v26i3.8652882

coordenação e a integração de partes desse objeto ou das suas vistas. Por exemplo, num estudo com crianças dos $3 .^{\circ}$ ao $5 .^{\circ}$ anos, Battista e Clements (1996) estudaram a forma como as crianças estruturam espacialmente construções com cubos. Para isso, forneceram modelos físicos, representações pictóricas, vistas das construções (de cima, de frente e de lado), ou planificações da construção (Figuras 1, 2 e 3), e perguntaram o número de cubos das construções. Assim, para construir os seus modelos, as crianças precisaram coordenar as diferentes vistas, reconhecendo como se relacionam espacialmente. Isto implica, por exemplo, compreender que um quadrado representado numa vista corresponde a um cubo, mas que o mesmo cubo pode estar ainda representado noutra vista por um outro quadrado. Porém, para construir o modelo mental da construção, os indivíduos precisam ainda de as integrar, construindo uma visão holística de um objeto único e coerente com essas vistas. Naturalmente, a integração pressupõe a coordenação.
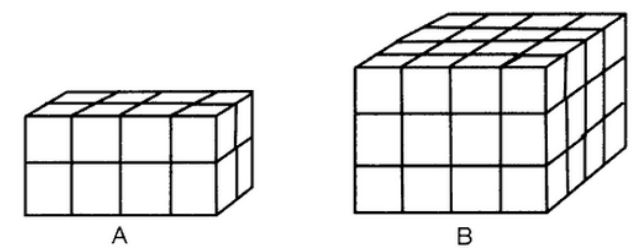

Figura 1 - Representação pictórica Fonte: Battista \& Clements, 1996, p. 260

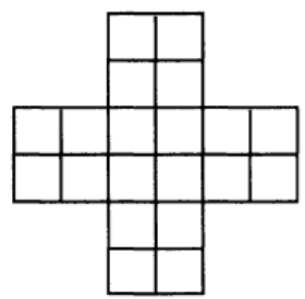

Figura 2 - Planificação Fonte: Battista \& Clements, 1996, p. 277
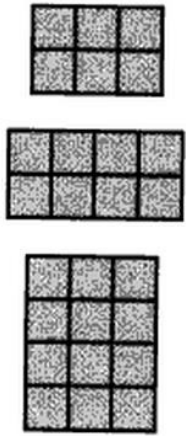

Figura 3 - Vistas

Fonte: Battista \&

Clements, 1996, p. 285

Battista e Clements (1996) colocam como hipótese dois processos que conduzem à integração. O primeiro recorre à memória — o aluno evoca algum objeto que conhece e que tenha semelhanças com o novo objeto e constrói o seu modelo mental por comparação com o objeto conhecido. Por exemplo, é natural construir um modelo mental de um antiprisma por comparação com um prisma. $\mathrm{O}$ segundo pode ocorrer se o indivíduo não recordar um objeto adequado à comparação — nesse caso, pode ativar um processo alternativo e que consiste em fazer transformações em imagens de objetos "disponíveis". Por exemplo, pode construir um modelo mental de uma construção paralelipípedica visualizando uma translação sucessiva de uma "camada" da construção (Figura 4).

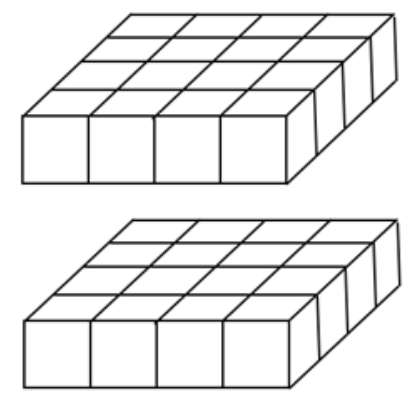


DOI: http://dx.doi.org/10.20396/zet.v26i3.8652882

Figura 4 - Construção paralelipipédica que resulta da integração de outros objetos ("camadas") Fonte: Imagem dos autores

No estudo de Battista e Clements (1996), era pedido às crianças que indicassem quantos cubos teria cada construção. Este tipo de tarefa corresponde ao que os autores designam por tarefa de contagem ou enumeração que, como mostram os resultados do seu estudo, influencia e é influenciada pela estruturação espacial. Por um lado, a estruturação espacial fornece o input e a organização para a contagem. É o que acontece quando, para determinar o número de arestas de um prisma pentagonal multiplicamos 3 por 5 - já sabemos que as arestas se encontram, em igual número, nas duas bases e nas arestas laterais. Por outro, as tentativas de contagem geram frequentemente a estruturação ou restruturação espacial. Neste caso, o aluno ainda não identificou esta organização, mas a contagem leva-o a perceber a existência daqueles três conjuntos com o mesmo número de arestas que se localizam de determinada maneira. De facto, no estudo de Battista e Clements, a tarefa de contagem promoveu uma análise "mais fina" e uma estruturação melhor dos objetos do que aquela que os alunos evidenciavam originalmente ao percecionar o objeto ou ao construí-lo. De certa forma, as ações físicas ou mentais que são realizadas durante a contagem tornam-se representações explícitas da estruturação dos objetos e a reflexão sobre essas ações capacita os alunos para reorganizar a estruturação dos objetos espaciais.

\section{Formação inicial de professores em geometria}

O crescente interesse pelo raciocínio espacial que referimos anteriormente não tem sido acompanhado de orientações curriculares consistentes, incluindo as dirigidas à formação de professores, como ilustra o caso americano. Nos Estados Unidos da América, o NCTM (1994) sugere que os professores dos anos iniciais devem compreender a forma como a geometria é usada para descrever o mundo em que vivemos e resolver problemas concretos devem saber analisar figuras bi e tridimensionais incluindo o estudo de pavimentações, simetria, famílias de polígonos e poliedros. Devem ainda a conhecer a geometria nas suas várias perspetivas, produzir argumentações e justificações e valorizar o raciocínio espacial. Em 2000, o Conference Board for the Mathematical Sciences ${ }^{4}$ (CBMS) elaborou um documento orientador para a formação de professores de matemática onde propôs que, no que se refere à geometria, todos os futuros professores que lecionam até ao $5^{\circ}$ ano desenvolvam as suas competências em várias áreas, incluindo o raciocínio espacial, nomeadamente através da familiarização com projeções, secções, decomposições de figuras comuns bi e tridimensionais; representação de objetos tridimensionais em duas dimensões e construção de objetos tridimensionais a partir de representações bidimensionais. O relatório mais recente do CBMS (2012) atualiza as ideias principais sobre a formação dos professores em geometria,

\footnotetext{
${ }^{4}$ Organização que congrega várias associações profissionais norte-americanas, como o National Council of Teachers of Mathematics (NCTM) e a American Mathematical Society (AMS).
} 
DOI: http://dx.doi.org/10.20396/zet.v26i3.8652882

alinhando-as com o documento Common Core State Standards ${ }^{5}$, e reduzindo a geometria a uma área pouco representada na preparação de professores daqueles anos e sem qualquer referência ao raciocínio espacial. Esta mudança confirma a falta de consenso sobre o conhecimento geométrico que os futuros professores devem desenvolver (Jones, Mooney \& Harries, 2000), o que é agravado pela existência diminuta de investigação sobre o conhecimento dos professores e futuros professores no âmbito da geometria (Chapman, 2013; Clements \& Sarama, 2011; Steele, 2013).

No que diz respeito à abordagem metodológica, Watson e Mason (2007) sugerem que o trabalho a desenvolver deve partir de tarefas que promovam o pensamento matemático dos futuros professores e desenvolvam a sua perceção sobre o poder dessas tarefas, uma orientação consistente com a ideia de Ponte e Chapman (2008) de que, na formação inicial, os futuros professores devem aprender segundo os mesmos métodos que se preconiza que venham a utilizar nas suas práticas. Nesta perspetiva, surge com especial interesse o ensino exploratório, um tipo de ensino assente essencialmente em tarefas de cunho exploratório e investigativo, onde cabe a quem aprende uma parte importante do trabalho de descoberta e construção do conhecimento e numa dinâmica de aula em que se reserva um espaço significativo ao trabalho dos alunos sobre as tarefas, a par de momentos de discussão coletiva e negociação de significados (Ponte, 2005).

A falta de atenção relativamente ao conhecimento de futuros professores na área da geometria é particularmente acentuada no âmbito do raciocínio espacial. A este respeito, por exemplo, Jones e Tzekaki (2016) referem que, até 2005, os estudos empíricos apresentados no âmbito das comunicações do $\mathrm{PME}^{6}$ revelaram "um interesse limitado nesta capacidade per $s i$, seu significado e definição, o seu papel no currículo e o seu desenvolvimento na escola" (p. 110). Este cenário não mudou no que se refere à caracterização ou desenvolvimento do raciocínio espacial em futuros professores (e professores em exercício), já que não há qualquer referência a investigações sobre este assunto na formação inicial nos anos subsequentes (2005-2015). Também no âmbito do CERME ${ }^{7}$, como afirma Kuzniak (2013), uma das linhas emergentes nos estudos apresentados no campo da geometria, desde a origem deste congresso, incide sobre o desenvolvimento de capacidades espaciais. Contudo, são poucos os estudos realizados na formação inicial de professores em geometria e nenhum se centra no raciocínio espacial, embora possam mencioná-lo a propósito de outro aspeto em estudo - o que confirma a falta de foco neste assunto. Alargando o espectro de pesquisa, a revisão de literatura realizada por Sinclair et al. (2016) incidente em revistas científicas, atas de encontros e livros editados desde 2008, revela que o raciocínio espacial constitui uma das tendências atuais da investigação no campo da geometria, mas todos os estudos referidos

\footnotetext{
de orientação para o ensino da língua inglesa, artes e matemática.

${ }^{6}$ Congresso Anual do International Group of Phycology of Mathematics Education.

${ }^{7}$ Congresso da European Society for Research in Mathematics Education.
}

${ }^{5}$ Common Core State Standars é um documento adotado na grande maioria dos estados dos EUA, desde 2009, que estabelece objetivos de aprendizagem por ano, desde o pré-escolar ao ensino secundário, que devem servir 
DOI: http://dx.doi.org/10.20396/zet.v26i3.8652882

envolvem crianças ou jovens do ensino básico ou secundário.

No contexto português, há a referir o estudo quantitativo de Menezes, Serrazina e Fonseca (2014), que envolveu mais de duas centenas de futuros professores e educadores de infância de três instituições de formação. Este estudo visou a avaliação do desenvolvimento do conhecimento de geometria com base nos dados recolhidos a partir de um teste de escolha múltipla. Apesar de não estar focado no raciocínio espacial, este foi um dos parâmetros analisados a partir da seleção de possíveis planificações do cubo. Os resultados revelam que a esmagadora maioria dos futuros professores reconhece uma planificação prototípica do cubo (entre 80 a $89 \%$ reconhece a planificação com a forma de T), mas menos de metade reconhece outras planificações, havendo uma delas que apenas é reconhecida por $13 \%$ dos respondentes. Estes resultados indiciam dificuldades dos futuros professores no raciocínio espacial, já que a escolha ampla da planificação prototípica pode resultar da memorização daquela configuração e a falta de reconhecimento das restantes é muito significativa e pouco suscetível de se alterar com a formação nas disciplinas de geometria.

Desta forma, a importância do desenvolvimento do raciocínio espacial, particularmente considerada para a aprendizagem da geometria, mas com uma forte influência na área da ciência, tecnologia, engenharia e matemática (as disciplinas STEM), como evidenciam alguns estudos (Whiteley, Sinclair \& Davis, 2015), contrasta com a fraca atenção que tem merecido no campo da investigação, particularmente na área da formação de professores. Assim, este estudo procura contribuir para o conhecimento sobre o raciocínio espacial dos futuros professores através dos seus processos e de tarefas que o podem promover, indo ao encontro das necessidades referidas por Sinclair et al. (2016).

\section{Metodologia de investigação}

\section{Opções metodológicas, participantes e recolha de dados}

Este estudo tem um propósito interventivo, visando modificar as práticas da formação inicial de professores e educadores, por forma a melhorar as suas aprendizagens e contribuir para o conhecimento sobre a sua formação, partindo da compreensão que construímos sobre a forma como desenvolvem o seu raciocínio geométrico. A investigação foca-se na aprendizagem em contexto, a partir da conceção de estratégias e ferramentas de ensino, pelo que optámos pela metodologia de investigação baseada em design (IBD), na modalidade de experiência de formação (Cobb, Confrey, diSessa, Lehrer \& Schauble, 2003) em que a professora (a primeira autora do artigo) tem também o papel de investigadora.

Os dados que apresentamos foram recolhidos durante o segundo ciclo da IBD, envolvendo uma turma de 25 formandos que frequentavam a disciplina de Geometria (2. ${ }^{\circ}$ ano da Licenciatura em Educação Básica8). Habitualmente, os participantes trabalhavam em grupos de três a cinco elementos, a partir de tarefas de natureza exploratória. Durante as aulas

\footnotetext{
${ }^{8}$ Em Portugal, os futuros educadores de infância e professores do $1 .^{\circ}$ ao $6 .^{\circ}$ ano começam por tirar uma licenciatura de três anos e depois um mestrado específico das áreas e dos anos em que vão ensinar.
} 
DOI: http://dx.doi.org/10.20396/zet.v26i3.8652882

discutiam as suas ideias no grupo e, a partir dessa discussão, apresentavam a sua resolução à turma que a discutia coletivamente. A turma mostrou-se sempre bastante empenhada e o ambiente de trabalho era muito bom. Os dados que apresentamos referem-se a dois grupos de formandos que, habitualmente, têm diferentes níveis de desempenho. O grupo de Maria, Helena e Cristina tem um desempenho elevado, muito embora as participantes demonstrem lacunas em conceitos trabalhados no passado. O grupo de Afonso, Mónica, Vânia e Sandra é um grupo que mostra mais dificuldades, tanto no domínio de conceitos trabalhados no ensino básico como na aquisição de novos conceitos e desenvolvimento de capacidades.

A recolha de dados foi feita a partir dos registos áudio e vídeo das aulas que foram ainda confrontados com a análise documental das produções escritas, muito embora não haja aqui referência a essas produções. Esta opção deriva do facto de os diálogos e os gestos captados nas imagens vídeo evidenciarem o raciocínio espacial dos participantes de uma forma mais clara. Como defendem Battista e Clements (1996), e tal como referimos anteriormente, as ações físicas e mentais (neste caso explanadas em parte nos diálogos) tornam-se representações explícitas da estruturação dos objetos, um elemento fundamental do raciocínio espacial.

Neste artigo apresentamos dados resultantes da aplicação da tarefa Sólidos platónicos truncados (Figura 5). A partir dela, a turma deveria identificar o número de vértices, arestas e faces dos sólidos platónicos e dos sólidos obtidos quando um plano secciona o sólido da forma sugerida pelo enunciado, bem como estabelecer e justificar relações entre os elementos dos sólidos. Para a resolução da tarefa, cada grupo tinha ao seu dispor peças encaixáveis (Figura 6) para que pudessem construir os sólidos platónicos. Optámos por esta tarefa pois ela envolve o trabalho com figuras tridimensionais que, na perspectiva de Gutiérrez (2017), é a área da matemática que implica uma maior exigência em termos do raciocínio espacial. Além disso, o facto de se partir de um tipo de sólido para gerar mentalmente outro é uma atividade que implica necessariamente a construção de imagens mentais, bem como a realização de operações e transformações das imagens mentais.

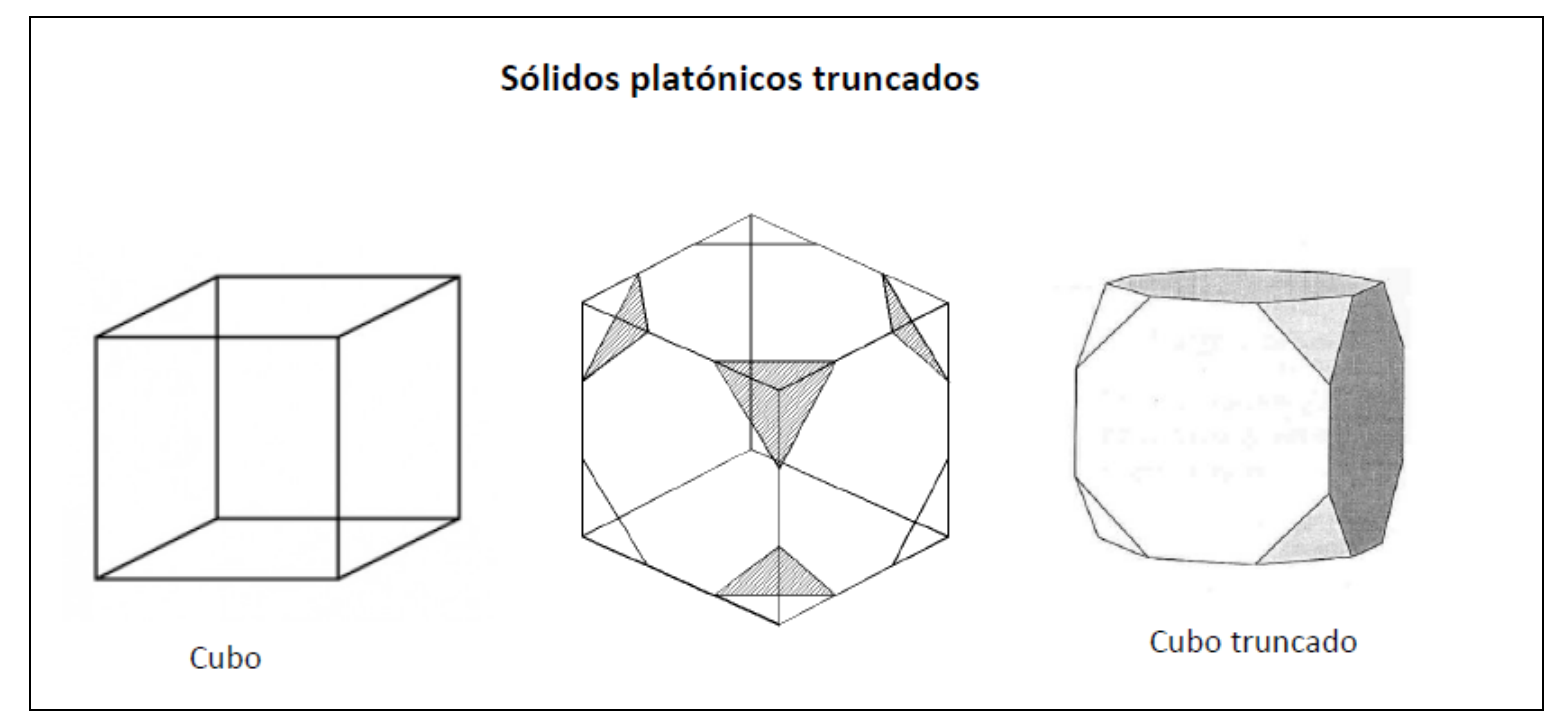


DOI: http://dx.doi.org/10.20396/zet.v26i3.8652882

Imagina que vamos cortar um cubo junto de cada vértice por um plano, de modo
a que a secção obtida seja um polígono regular, tal como mostra sequência de figuras
que termina no cubo truncado.
1. No caso do cubo truncado, as faces correspondentes às secções são triângulos
equiláteros e as restantes octógonos regulares. Observa os outros sólidos
platónicos e diz como serão as faces dos sólidos platónicos truncados.
2. Quantos vértices, arestas e faces tem o cubo truncado? E os outros poliedros
truncados? Preenche a tabela da página seguinte.
3. Observa os dados e compara-os. Estabelece as seguintes relações e procura
justificá-las.
a. Qual a relação entre o número de vértices do sólido original e do sólido
truncado?
b. E entre o número de faces?
c. E de arestas?
Sugestão: Além de observares os valores, pensa na forma como chegaste até
eles.

Figura 5 - Tarefa proposta

Fonte: Tarefa dos autores, adaptada de Projeto Matemática para Todos, s.d.

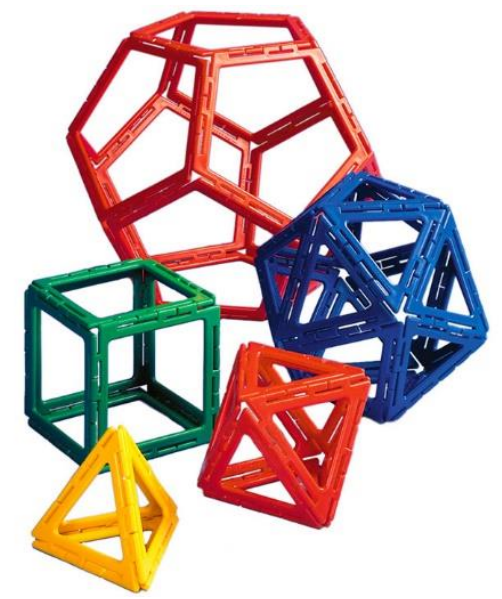

Figura 6 - Material disponibilizado a cada grupo

Fonte: Foto disponível em http://www.polydron.co.uk/polydron-frameworks.html

Análise de dados

Para analisarmos o raciocínio espacial desenvolvido durante a atividade de contagem e estabelecimento de relações na classe dos sólidos platónicos, utilizamos um quadro de análise que construímos a partir das ideias de Battista (2009) e Gutiérrez (1996) sobre raciocínio espacial que, do nosso ponto de vista, se complementam.

Desta forma, consideramos que o raciocínio espacial inclui, por um lado, a construção mental de imagens e modelos sobre objetos espaciais e relações e, por outro, a análise e realização de transformações e operações entre objetos e relações usando as imagens e modelos mentais, ainda que se possam suportar em representações externas (Quadro 1). 
DOI: http://dx.doi.org/10.20396/zet.v26i3.8652882

Quadro 1 - Processos de raciocínio espacial

\begin{tabular}{|l|l|}
\hline \multicolumn{1}{|c|}{ Processos } & \multicolumn{1}{c|}{ Subprocessos } \\
\hline \multirow{4}{*}{ Construção dos modelos mentais } & Interpretação visual da informação \\
\cline { 2 - 2 } & Identificação de subconjuntos do objeto \\
\cline { 2 - 2 } & Coordenação dos subconjuntos do objeto \\
\cline { 2 - 2 } $\begin{array}{l}\text { Análise e transformação de modelos mentais e } \\
\text { operações com modelos mentais }\end{array}$ & Observação e análise de imagens mentais \\
\cline { 2 - 2 } & $\begin{array}{l}\text { Transformação de imagens mentais noutras } \\
\text { imagens mentais }\end{array}$ \\
\cline { 2 - 2 } & $\begin{array}{l}\text { Transformação de imagens mentais noutro tipo de } \\
\text { informação }\end{array}$ \\
\hline
\end{tabular}

Fonte: Quadro elaborado pelos autores

A construção de modelos inclui a interpretação visual da informação (como perceber quais as características do plano de corte a partir das secções apresentadas), a identificação de subconjuntos do objeto (como decompor um sólido noutros sólidos ou em partes do sólido, como as faces), a coordenação de subconjuntos do objeto (implica identificar relações entre os subconjuntos, por exemplo, perceber se duas faces que se situam em subconjuntos diferentes são adjacentes ou partilham algum vértice) e a integração dos subconjuntos do objeto (que se traduz, por exemplo, na construção da imagem de um sólido a partir do conhecimento sobre a suas faces). A análise, transformação e operação com modelos mentais inclui a observação e análise de imagens mentais (conduz, por exemplo, a identificar o número de arestas em torno de um vértice), a transformação de imagens mentais noutras imagens mentais (como identificar qual a face resultante de uma secção do sólido por um determinado plano) e a transformação de imagens mentais noutro tipo de informação (por exemplo, generalizar que o número de vértices de um sólido platónico truncado corresponde ao produto do número de vértices do sólido platónico pelo número de arestas convergentes no mesmo vértice).

\section{Resultados}

Nesta secção, apresentamos e analisamos dados de vários episódios ocorridos durante a resolução da tarefa em grupos.

\section{Episódio A}

Sandra, Vânia, Afonso e Mónica estão numa fase inicial da resolução da tarefa e estão a contar o número de faces, vértices e arestas de um cubo truncado. Este é o único sólido cuja representação bidimensional aparece no enunciado, mas para os auxiliar já construíram os cinco poliedros regulares com o material disponibilizado. No diálogo que se segue discutem o número de arestas:

Sandra: Dá-me 40. 3 e 3 são 6, mais 6 são 12 [contou as arestas das faces triangulares no topo]. $12+12$ são 24 [juntou às da base]. 25, 26, 28, 28 [circunda uma face lateral, figuras 7, 8 e 9], 29, 30, 31, 32 [outra], 33,34,35,36 [outra], 37, 38, 39, 40! [a $4^{\text {a }}$ face lateral]. 

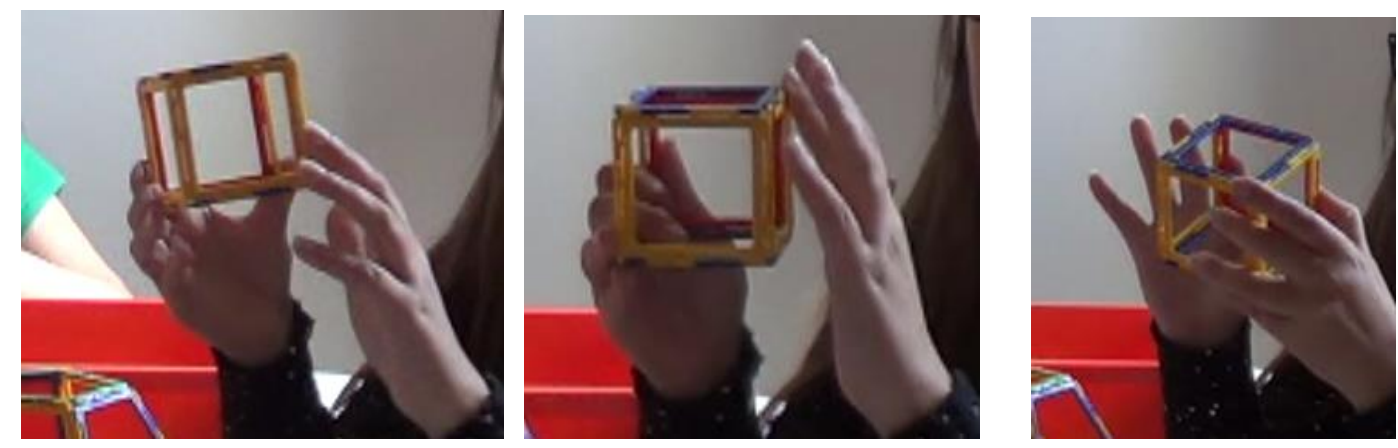

Figuras 7, 8, 9 - Sandra conta as arestas de um cubo truncado a partir do cubo Fonte: Fotos dos autores

Sandra: É o número de arestas do cubo mais 24 porque é o número de arestas que se acrescenta. $12+12,24$.

Vânia: Tem de ser 48. Quanto é que vos deu as arestas?

Afonso: 40.

Vânia: A nós deu-nos 48.

Afonso: Repara, quantas arestas é que tu já tens?

Vânia: Nós não fizemos assim. Tu tens em cada face um octógono. Então sabes que são 8 arestas em cada lado, então fazes $8,8,8,8,8,8$ [aponta para cada face do sólido]. 6 vezes 8 .

Afonso: Mas a nós deu-nos 40. Só se nos enganámos.

Sandra: Acho que faltam os de cima [volta a repetir o que fizeram]. Esquecemo-nos de contar as de cima e as de baixo que são 4+4, 8. Dá 48.

Afonso: Não! Mas ao contares estas já estás a contar as de cima! Logo é 40.

Neste momento, a professora passa pelo grupo e alerta para o que diz o Afonso:

Professora: Reparem que isto [apontando para as arestas do modelo físico] é só uma aresta!

Sandra: Então ainda dá menos do que 40!

Sandra e o Afonso voltam ao cubo, contam as arestas (12):

Sandra e Afonso: Então $12+24$. Dá 36!

Neste episódio podemos observar como o mesmo objeto pode ser estruturado de formas diferentes, o que é evidenciado pela forma como os formandos tornam explícitas as suas contagens. As ações de Sandra e Afonso sugerem um modelo mental que resulta da identificação de subconjuntos do objeto: a composição das faces triangulares (e respetivas arestas) com as arestas do cubo que surgem associadas às arestas das quatro faces laterais. Contudo, a integração dos vários elementos não é correta devido a um problema de 
DOI: http://dx.doi.org/10.20396/zet.v26i3.8652882

coordenação — não identificam inicialmente que estão a duplicar a contagem de quatro arestas. Já Vânia e Mónica (que não intervém neste diálogo apesar de estar a trabalhar com a colega) revelam um modelo que resulta também da identificação de subconjuntos do objeto: a composição de 6 octógonos e respetivas arestas, o que não requer a contagem separada das arestas das faces triangulares. No entanto, também este par erra na contagem pelo mesmo problema identificado no raciocínio dos colegas — a coordenação dos 6 octógonos que têm 12 arestas em comum.

Apesar dos erros, Sandra já havia identificado que o número de arestas do sólido truncado é a soma do número de arestas do sólido original com o número de arestas que resultam da secção. Esta relação resulta da transformação de imagens mentais noutro tipo de informação e, curiosamente, é a sua aplicação e o confronto de resultados diferentes que os leva a repensar as suas estratégias e a restruturar o sólido. Há ainda a referir que, se o material disponível foi fundamental para realizar as contagens, possibilitando a realização de ações que explicitam o modelo mental, também há a possibilidade de induzir o erro de duplicação de arestas, pelo facto de fisicamente existirem lados que se encaixam para formar uma aresta mas não se "fundem".

\section{Episódio B}

Afonso e Mónica estão a determinar o número de faces, vértices e arestas de outros sólidos truncados sobre os quais não existe qualquer representação externa. No início deste episódio estão a analisar o icosaedro truncado:

Afonso: O número de vértices, ou seja 12, vezes 5. Percebes porque é que é? Mónica: Não.

Afonso: Vamos fazer com este [octaedro]. Então é assim: cada vértice, quando tiver a face truncada ${ }^{9}$, essa face vai ficar com o número de lados que é o número de arestas que converge nesse vértice. E depois só temos de multiplicar pelo número de vértices.

Mónica: Ah! Já percebi.

Neste diálogo é percetível que Afonso já encontrou uma relação entre o número de vértices do sólido original e do sólido truncado e explica-a a Mónica. Esta relação pressupõe a construção de uma imagem mental da face truncada em que os vértices da nova face se situam nas arestas que convergem num vértice do poliedro original, ou seja, a transformação de imagens mentais noutras imagens mentais. Ao encontrar a relação referida, Afonso procede à transformação de imagens mentais noutro tipo de informação. A utilização desta expressão é representativa de uma situação em que é a estruturação espacial do sólido que determina a contagem e não o contrário.

No próximo passo, vão analisar o dodecaedro truncado, mas começam por registar o

\footnotetext{
${ }^{9}$ Para simplificar, consideremos que a expressão "face truncada" corresponde à nova face que se obtém quando o poliedro é truncado.
} 
DOI: http://dx.doi.org/10.20396/zet.v26i3.8652882

número de vértices do dodecaedro. Mónica segura no sólido e Afonso conta (Figura 10):

Afonso: 1, 2, 3, 4, espera. Já contaste este?
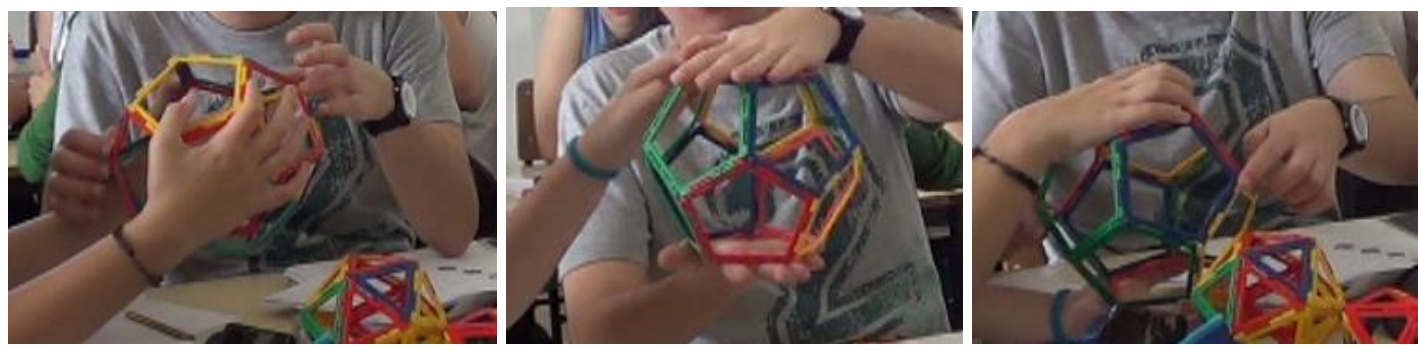

Figuras 10, 11 e 12 - Mónica e Afonso contam os vértices do dodecaedro Fonte: Fotos dos autores

Afonso: Põe assim que é mais fácil [Figura 11]. Estão 5 aqui e 5 aqui [pentágono na base e no topo]. ... 1, 2, 3, 4, 5, 6, 7, 8, 9, 10 [Figura 12]. OK 10. Então são...

Mónica: 20.

Afonso: 5, 5, 10. Sim, são 20.

Afonso: Agora número de vértices do sólido truncado... é só fazer 5 vezes 20. Vamos ver porquê. O número de arestas que converge...

Mónica: É 3, agora é 3.

Afonso: Ah, pois é, agora é triângulos [a face truncada]. 60.

Mónica: Então, número de faces do sólido truncado. Então este é 12. Somar as faces truncadas 20. 20+12.

Afonso: Outra vez?! [no icosaedro fez a mesma operação]. Ah, sim! Só que agora é ao contrário! Antes era 12 vértices e 20 faces e agora é 12 faces e 20 vértices!

Afonso: São 32 .

Nesta interação, vemos que a determinação do número de vértices do dodecaedro truncado surge naturalmente da relação encontrada e Mónica parece encontrar sentido nessa relação que Afonso lhe explicou, já que é ela própria que corrige o colega ao dizer que deve multiplicar por 3 e não por 5. Curiosamente, o que parece ser mais desafiante é a contagem dos vértices do sólido original. De facto, o dodecaedro é o poliedro regular que tem mais vértices e é importante, mais do que nos outros sólidos, encontrar uma organização mental que nos permita realizar a contagem eficazmente. A primeira tentativa deste par foi percorrer, aparentemente sem critério, todos os vértices, uma abordagem que foi rapidamente abandonada. A estratégia que usaram depois mostra que, por um lado, a posição do sólido é relevante, em particular pelo posicionamento de uma face na horizontal, como se tratasse de uma base. Por outro lado, a forma de contar mostra que o modelo mental que estão a construir resulta da identificação dos subconjuntos do objeto: os 5 vértices da face topo, os 5 
DOI: http://dx.doi.org/10.20396/zet.v26i3.8652882

vértices da face "base" e os 10 vértices que se encontram na zona central do poliedro e que formam uma espécie de ziguezague. Desta forma, neste caso é a tarefa de contagem e as ações que desencadeia que sugerem uma estruturação do sólido.

Ainda neste episódio vemos que o par de formandos já percebeu que para contar o número de faces de um sólido truncado tem de adicionar o número de faces do sólido original com o seu número de vértices (de novo transformação de imagens mentais noutro tipo de informação). Note-se que o resultado obtido para o dodecaedro truncado (32) é o mesmo que o resultado para o icosaedro truncado, o que é notado por Afonso, uma observação que poderia ser explorada mais ainda pelo facto de o icosaedro ser dual do dodecaedro e viceversa.

\section{Episódio $C$}

De seguida, Afonso e Mónica passam à contagem das arestas do dodecaedro. Afonso pede para colocar o sólido de novo na posição em que contaram os vértices. Já sabem que têm 5 arestas em cada pentágono na face topo e na base e vão contar as restantes (Figura 13):

Afonso: Então agora é 4... Não... 13, 14... Contámos bem?!

Voltam a contar várias vezes, mas algumas vezes reparam que estão a contar a mesma aresta mais do que uma vez e vão obtendo valores diferentes. Ao fim de várias tentativas chegam à seguinte organização (Figura 14):

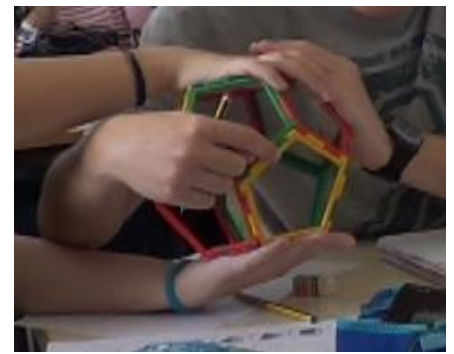

Figura 13 - Mónica e Afonso contam as arestas do dodecaedro Fonte: Foto dos autores

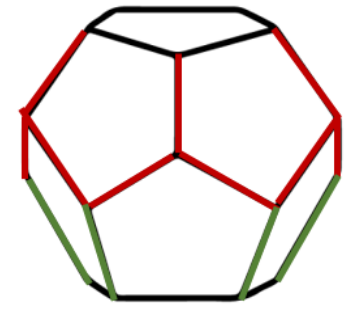

Figura 14 - Dodecaedro decomposto em subconjuntos

Fonte: Imagem dos autores

Afonso: [conta as vermelhas] ... 14, 15. 5 [pentágono topo], 5 [pentágono na base], só falta as de lado, 5 [verdes].

Mónica: Então 25, são 30 [no dodecaedro].

Afonso: Então são 90 [arestas no dodecaedro truncado]?! Não pode ser! Número de vértices, são 20. É 20 vezes 3 mais 30. Percebes porquê? As já existentes [30], e depois é o número de vértices [do dodecaedro] que é 20 vezes o número de arestas que converge num vértice. Então é 90.

Neste diálogo observamos a construção do modelo mental do dodecaedro, mas desta vez focado nas arestas. De facto, embora se trate do mesmo objeto que já foi analisado anteriormente, agora o foco são as arestas e não os vértices, o que faz com que a análise se concentre noutras relações entre os elementos. Para contar eficazmente as arestas, tal como já 
DOI: http://dx.doi.org/10.20396/zet.v26i3.8652882

acontecera com os vértices, Mónica e Afonso identificam subconjuntos do objeto cuja integração resulta no dodecaedro. Contudo, além desta decomposição, o processo de estruturação espacial em causa implica coordenar os diferentes subconjuntos, o que é essencial para perceber que há arestas que correspondem a faces diferentes e não duplicar a sua contagem. Uma vez encontrada essa estrutura, Mónica e Afonso obtiveram o número de arestas do dodecaedro e, em seguida, do dodecaedro truncado. No entanto, para o primeiro sólido foi a tarefa de contagem das arestas que determinou a estruturação geométrica; para o segundo, foi a estruturação geométrica que utilizou a identificação do número de arestas, uma vez que o par já identificou a relação entre as arestas do sólido original e do sólido truncado.

\section{Episódio D}

Mónica e Afonso identificaram todas as relações pedidas e o número de faces, vértices e arestas dos poliedros truncados. Contudo, a professora pediu-lhes para completarem a resposta à primeira questão, sobre o tipo de faces de cada novo poliedro, uma vez que só tinham referido a face que se obtém ao truncar o sólido e omitiram a forma da face original depois de transformada. No diálogo seguinte estão a analisar o tetraedro truncado:

Afonso: É um quadrilátero assimétrico. Não sei. Quando se corta o tetraedro fica assim [Figura 15]... Não sei dizer bem qual é o quadrilátero...
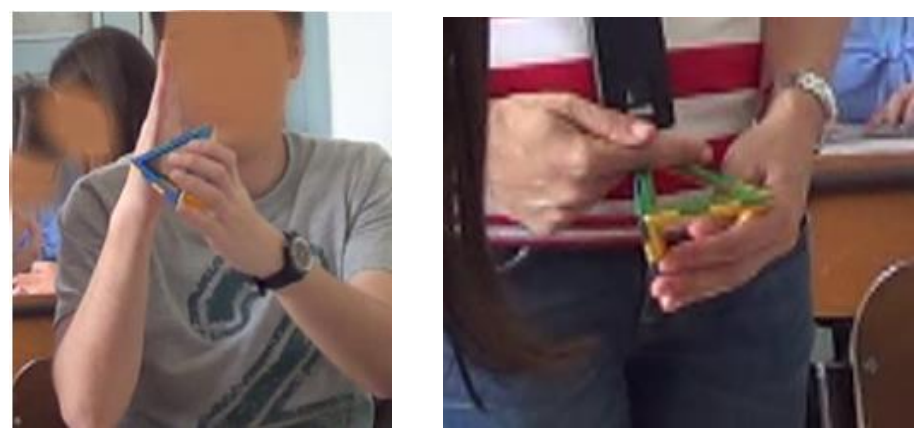

Figuras 15 e 16 - Afonso e a professora simulam como ficam as faces triangulares quando o cubo é truncado Fonte: Fotos dos autores

Professora: Ah! Já estou a perceber. A outra face fica um quadrilátero, qual é esse quadrilátero?

Afonso: Pois é essa a questão. A Mónica diz que é um paralelogramo.

Professora: Mas não se esqueçam que o que acontece a este vértice vai acontecer aos outros também! Portanto, têm de fazer assim [Mónica coloca as mãos também, Figura 17] 
DOI: http://dx.doi.org/10.20396/zet.v26i3.8652882

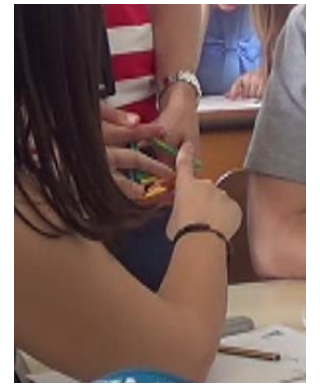

Figura 17 - Mónica simula com a professora como fica uma face triangular depois de truncar três vértices Fonte: Foto dos autores

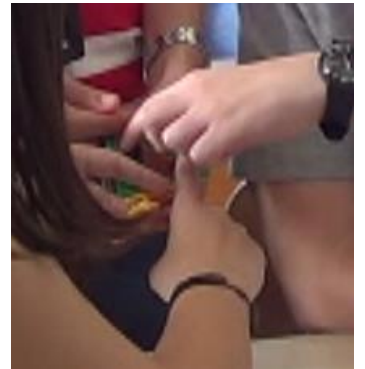

Figura 18 - Afonso conta o número de arestas da nova face Fonte: Foto dos autores

Afonso: Ah, sim, já percebi. Tem 1, 2, 3, 4, 5, 6 [contorna a figura formada, Figura 18]. OK, já percebi. É um... pentágono? Não, um hexágono.

Professora: Mas agora pensem lá... O Afonso contou um a um, usando o seu dedo. Não existe uma lógica que me permita perceber quantos lados é que eu vou ter?

Afonso: Ah! Basta contar o número de vértices e o número de lados já existentes!

Professora: Ou seja? Isso não é o mesmo número? Ou seja, aqui [tetraedro] tens 3 lados e 3 vértices. Passaste a ter?

Afonso: Um hexágono, sim.

Professora: É importante a estrutura da figura para nós percebermos o que está a acontecer.

Num outro momento, a professora passa pelo grupo e Afonso aborda-a:

Afonso: Nós estivemos a ver a figura e deu-nos em todos um hexágono.

Professora: Em todos?

Afonso: Sim.

Professora: Então vamos lá pensar naquela relação que tu disseste há bocado. Portanto, quando temos triângulos nas faces vamos passar a ter hexágonos. Foi o que aconteceu no tetraedro, e aqui [octaedro]?

Afonso: Também um triângulo, vai acontecer o mesmo.

Professora: Portanto ficamos com hexágonos. No icosaedro idem. E no dodecaedro?

Afonso: Também porque convergem 3 arestas num vértice. Ah não! Pois é, não pode ser. Então fica... é multiplicar, não? 1, 2, 3, 4, 5, 6, 7, 8, 9, 10. É um...

Mónica: Já falámos disso aqui. 
DOI: http://dx.doi.org/10.20396/zet.v26i3.8652882

Professora: Então qual é o prefixo de $10 \ldots$

Anteriormente, Afonso havia determinado corretamente o tipo de face que surge nos poliedros quando os truncamos e justificou o número de vértices dessa face. Esta ação implica uma transformação do modelo mental do poliedro original, através da transformação de imagens mentais noutras imagens mentais, dando origem a um novo modelo - o do poliedro truncado. Contudo, como é visível neste episódio, os formandos não tiveram o mesmo sucesso em transformar mentalmente as faces existentes. No caso do tetraedro, foi necessária uma simulação com materiais e a realização de ações físicas para contar o número de arestas do hexágono resultante, ou seja, foi necessário ir além de uma operação mental. Mesmo depois da análise do tetraedro truncado, não foi fácil generalizar a relação pois Afonso considerava que seriam sempre hexágonos e foi a professora que lhe sugeriu repensar esta conclusão.

Desta forma, podemos perceber que mesmo tendo descoberto anteriormente todos os valores corretos para o número de arestas, vértices e faces dos poliedros truncados e um dos tipos de faces, estes formandos não tinham ainda uma estruturação completa dos sólidos, mas sim uma estruturação local, focada nas faces truncadas.

\section{Episódio E}

Neste episódio analisamos o raciocínio de outro grupo que discute a forma das faces de um dodecaedro truncado. Anteriormente as formandas já tinham acordado que as faces truncadas resultam em triângulos, pelo que neste diálogo se debruçam sobre a forma como ficam transformadas as faces pentagonais do dodecaedro:

Maria: Desculpa, mas como é que isto dá pentágonos e triângulos????

Helena: Porque se vais cortar um bocado aqui, um bocado aqui, um bocado aqui...

Maria: Mas não ficam pentágonos!

Helena: Isto aqui! Nesta face [em vez do pentágono original] fica!

Maria: Como é que ficam pentágonos?! Fica o dobro!

Helena: O dobro???? Isto daqui é um pentágono! Quando tu cortas até aqui ao meio neste fica um pentágono ao contrário.

Maria: Um pentágono??... Não fica 1, 2, 3, 4, 5, 6, .. 10 lados! Estás a fazer isso mal!

Helena: Porquê????

Maria: Desculpa, tu não estás a ver bem! Como é que fica o mesmo número de lados se tu vais acrescentar 5 arestas? Como é que fica um pentágono na mesma? Porque isto não une! Ou une? Se calhar une!

Cristina: O problema é que se calhar une...

Maria: Pois eu não pus a unir... 
DOI: http://dx.doi.org/10.20396/zet.v26i3.8652882

Cristina: Pois porque se este unisse, aqui [no cubo truncado] também era quatro lados [em vez dos octógonos]. Então como é que se diz como 10 lados? Deca... Decágono...

Maria: Decágono??? Professora! Como é que se chama um polígono com 10 lados?

Nesta acesa discussão, Maria e Helena começam por discordar relativamente à nova face-Maria considera que obterá decágonos e Helena outros pentágonos. Na verdade, essa discordância resulta de diferentes interpretações sobre os pontos de interseção do plano de corte, ou seja, a interpretação visual da informação, um aspeto ainda não focado pelo facto de não terem surgido interpretações alternativas nos episódios anteriores. Concretamente, Maria considerou que o plano interseta as arestas do sólido dividindo-as em três partes, ou seja, de acordo com o exemplo do enunciado; Helena considerou que o plano de corte interseta as arestas nos seus pontos médios, uma interpretação alternativa ao enunciado; Cristina acaba por esclarecer qual deve ser a interpretação procurando aquela que é consistente com o cubo truncado. Desta forma, Maria e Cristina mostram construir uma imagem mental correta da nova face, pois além de identificarem corretamente a sua forma, percebem que o número de arestas da face resultante é o dobro do número de arestas da face original. Já Helena deu uma resposta que é incorreta mas, apesar disso, reveladora de um bom raciocínio espacial. De facto, se as condições que definem o plano de corte fossem as que considerou, a face resultante seria igualmente um pentágono que, efetivamente estaria noutra posição. Aliás, é curioso que as suas condições são as que definem um novo poliedro arquimediano, um icosidodecaedro (Figura 19).
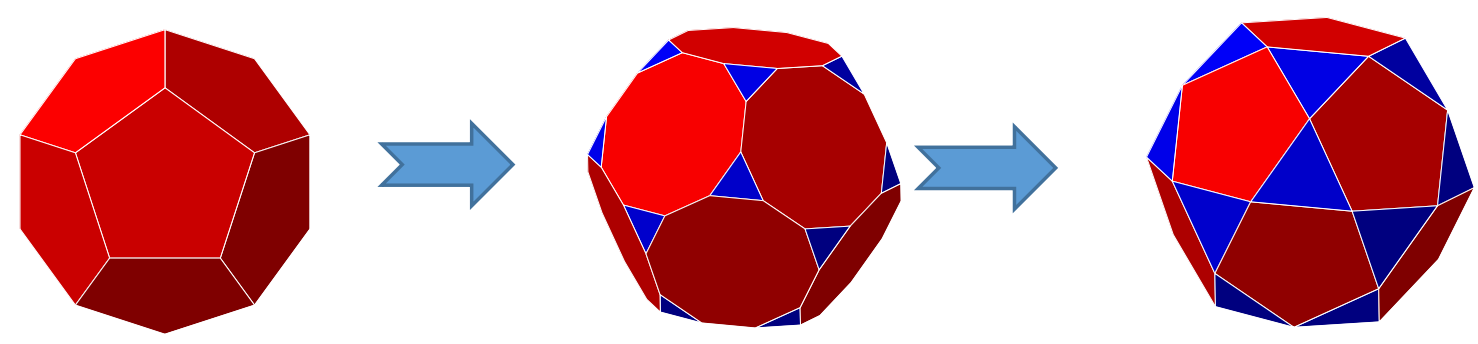

Figura 19 - Construção do dodecaedro truncado e icosidodecaedro Fonte: Esquema elaborado pelos autores

Desta forma, consideramos que no âmbito desta tarefa Maria, Helena e Cristina revelam ter sucesso na transformação de imagens mentais noutras imagens mentais.

\section{Discussão}

A análise da forma como os participantes resolveram a tarefa revelou vários aspetos sobre os processos de raciocínio espacial em que se envolveram e que destacamos nesta secção. Por um lado, verificamos que os futuros professores construíram modelos mentais sobre os sólidos platónicos e sobre os sólidos platónicos truncados, analisaram, transformaram e operaram com estes modelos, o que já era esperado atendendo ao que era 
DOI: http://dx.doi.org/10.20396/zet.v26i3.8652882

pedido na tarefa. Analisando mais detalhadamente estes processos, percebemos que o trabalho realizado envolveu ainda todos os subprocessos que considerámos no quadro de análise, ainda que com níveis de desafio diferentes.

$\mathrm{Na}$ construção de modelos mentais, a interpretação visual da informação e a identificação de subconjuntos dos objetos que integrados resultassem no objeto completo parecem ser processos que os participantes realizaram com alguma facilidade; já a coordenação dos subconjuntos constituiu um desafio maior, uma vez que surgiram alguns erros de duplicação de arestas. Para a superação deste desafio contribuíram especialmente a manipulação física dos sólidos e a explicitação verbal dos modelos mentais que os participantes tinham dos sólidos. De facto, tratam-se de representações externas que, tal como refere Gutiérrez (1996), ajudam a realizar raciocínio espacial.

Do ponto de vista da análise, transformação e operação sobre os modelos mentais, consideramos que a observação e análise de imagens mentais foi um processo realizado com sucesso na maioria das vezes, o que contribuiu para a transformação de imagens mentais noutro tipo de informação - neste caso, a explicitação das relações entre os elementos dos sólidos. Já a transformação de imagens mentais noutras imagens mentais assume diferentes níveis de dificuldade, tal como vimos na determinação da forma das faces do sólido truncado, o que provavelmente decorre da complexidade do objeto e da operação a realizar. No entanto, destacamos que, mais uma vez, foi determinante a manipulação física dos sólidos e a explicitação verbal dos modelos mentais para o raciocínio correto.

Um outro aspeto que destacamos diz respeito às formas de estruturar um objeto que, como refere Battista (2009), podem ser diferentes. De facto, como os dados sobre a contagem de vértices e arestas do dodecaedro mostram, não só diferentes indíviduos constroem modelos mentais diferentes, como a própria questão pode desencadear a construção de um modelo diferente para o mesmo objeto, o que afeta o raciocínio espacial. Além destas diferenças, percebemos ainda que, por vezes, a estruturação dos objetos é apenas local, ou seja, pode não existir um modelo para todo o objeto mas apenas de partes do objeto, sem haver integração.

Finalmente, centremo-nos no papel da tarefa. Tal como concluíram Battista e Clements (1996) no seu estudo, a atividade influenciou e foi influenciada pela forma como os individuos estruturam os objetos. Neste caso, parece-nos que a mobilização de vários processos de raciocínio espacial foi particularmente promovida por alguns fatores: a complexidade dos sólidos utilizados e da operação de secção por um plano que deve ser adequada aos indivíduos a que se destina, mantendo um nível de desafio cognitivo elevado mas alcançável; a existência de modelos físicos para os sólidos platónicos e a inexistência do mesmo tipo de modelo para os truncados que obrigou a um trabalho mental que não seria realizado se existissem os modelos para todos os sólidos; o pedido do número de faces, vértices e arestas que, associada à complexidade dos objetos, implica a sua estruturação; o estabelecimento de relações e sua justificação que reforça a necessidade de estruturação.

Além do enunciado da tarefa, temos a forma como foi realizada. Como os diálogos 
DOI: http://dx.doi.org/10.20396/zet.v26i3.8652882

mostram, a interação entre os participantes com a comunicação dos seus raciocínios foi um elemento determinante para o sucesso da atividade. Em várias ocasiões, o confronto de respostas diferentes resultou na revisão do raciocínio dos futuros professores ou no seu enriquecimento, decorrente da diversidade de perspetivas. De facto, apesar do raciocínio espacial apelar a uma atividade centrada em imagens mentais, eventualmente mais difíceis de partilhar, sublinhamos a relevância do trabalho de natureza exploratória (Ponte, 2005), com uma forte componente de discussão e negociação de resultados que, também neste tema e no âmbito da formação inicial de professores, se revela fundamental.

\section{Conclusão}

O desenvolvimento do raciocínio espacial envolve a realização de processos associados à construção, análise, transformação de modelos mentais e operações com modelos mentais (Battista, 2009; Gutiérrez, 1996). Este estudo sugere que há várias condições que são relevantes para a ativação destes processos, em particular, no que respeita ao tipo de tarefas propostas, os recursos disponibilizados e as interações na sala de aula. No que respeita às tarefas, a seleção dos sólidos e das operações mentais deve manter o nível de desafio cognitivo elevado, mas alcançável; a realização de contagens de elementos dos poliedros e o estabelecimento de relações e justificações revelam-se promotores dos processos de raciocínio espacial; o material manipulável é importante como suporte, mas a sua utilização não deve diminuir o desafio cognitivo, nomeadamente, substituindo ou sobrepondo-se às imagens mentais; e o contexto de trabalho colaborativo favorece a comunicação do raciocínio que, por sua vez, estimula a estruturação e restruturação espacial dos objetos. Desta forma, a formação inicial de professores deve promover as condições necessárias à realização deste tipo de trabalho, valorizando o raciocínio espacial como uma componente fundamental do raciocínio.

\section{Agradecimentos}

O presente artigo foi realizado no âmbito do projeto $\mathbf{O}$ raciocínio geométrico e a visualização espacial na formação inicial de professores dos primeiros anos sedeado no Centro Interdisciplinar de Estudos Educacionais — referência ESEXL/IPL-CIED/2016/A12.

\section{Referências}

Atiyah, M. (1982). What is geometry? The 1982 Presidential Address. The Mathematical Gazette, 66(437), 179-184.

Battista, M. T. (2007). The development of geometric and spatial thinking. In F. K. Lester (Ed.), Second handbook of research on mathematics teaching and learning (pp. 843908). Greenwich, CN: Information Age.

Battista, M. T. (2009). Highlights of research on learning school geometry. In T. V. Craine \& R. Rubenstein (Eds.), Understanding geometry for a changing world (pp. 91-108). Reston, VA: NCTM. 
DOI: http://dx.doi.org/10.20396/zet.v26i3.8652882

Battista, M. T., \& Clements, D. H. (1996). Students' understanding of three-dimensional rectangular arrays of cubes. Journal for Research in Mathematics Education, 27(3), 258-292.

Chapman, O. (2013). Investigating teachers' knowledge for teaching mathematics. Journal of Mathematics Teacher Education, 16(4), 237-243.

Cobb, P., Confrey, J., diSessa, A., Lehrer, R., \& Schauble, L. (2003). Design experiments in educational research. Educational Researcher, 32(1), 9-13.

CBMS (2000). Mathematical Education of Teachers Project. Washington, DC: American Mathematical Society.

CBMS (2012). Mathematical Education of Teachers II. Washington, DC: American Mathematical Society.

Clements, D. H., \& Sarama, J. (2011). Early childhood teacher education: the case of geometry. Journal of mathematics teacher education, 14(2), 133-148.

Duval, R. (1999). Representation, vision and visualization: Cognitive functions in mathematical thinking. Basic issues for learning. In F. Hitt \& M. Santos (Eds.), Proceedings of the 21st North American PME Conference, 1, 3-26.

Gutiérrez, A. (1996). Visualization in 3-dimensional geometry: In search of a framework. In L. Puig \& A. Gutierrez (Eds.), Proceedings of the 20th PME International Conference, 1, 3-19.

Johnston-Wilder, S., \& Mason, J. (Eds.). (2005). Developing thinking in geometry. London: Sage.

Jones, K., Mooney, C., \& Harries, T. (2002). Trainee primary teachers' knowledge of geometry for teaching. Proceedings of the British Society for Research into Learning Mathematics, 22(2), 95-100.

Jones, K., \& Tzekaki, M. (2016). Research on the teaching and learning of geometry. In A. Gutiérrez, G. C. Leder \& P. Boero (Eds.), The second handbook of research on the psychology of mathematics education (pp. 109-149). Rotterdam: Sense.

Kuzniak, A. (2013). Teaching and learning geometry and beyond... In B. Ubuz, Ç. Haser \& M. A. Mariotti (Eds.), Proceedings of the eighth congress of the European Society for Research in Mathematics Education (pp. 33-49). Turkey: Ankara.

Malkevich, J. (2009). What is geometry? In T. V. Craine \& R. Rubenstein (Eds.), Understanding geometry for a changing world (pp. 3-16). Reston, VA: NCTM.

Menezes, L., Serrazina, L., Fonseca, L., Ribeiro, A., Rodrigues, M. Vale, I., ... Tempera, T. (2014). Conhecimento de geometria de alunos da licenciatura em Educação Básica. Atas do XXV Seminário de Investigação em Educação Matemática. Braga.

National Council of Teachers of Mathematics (NCTM) (1994). Normas profissionais para o ensino da Matemática. Lisboa: APM e IIE.

Ponte, J. P. (2005). Gestão curricular em Matemática. In GTI (Ed.), O professor e o desenvolvimento curricular (pp. 11-34). Lisboa: APM.

Ponte, J. P. \& Chapman, O. (2008). Preservice mathematics teachers' knowledge and development. In L. English (Ed.), Handbook of international research in mathematics education ( $2^{\text {nd }}$ ed., pp. 225-263). New York, NY: Routledge.

Presmeg, N. C. (2006). Research on visualization in learning and teaching mathematics. In A. 
DOI: http://dx.doi.org/10.20396/zet.v26i3.8652882

Gutiérrez, P. Boero (Eds.), Handbook of Research on the Psychology of Mathematics Education: Past, Present and Future (pp. 205-235). Rotterdam: Sense.

Projecto Matemática para Todos (s.d.). Investigações na sala de aula-propostas de trabalho. Lisboa: APM

Sinclair, N., Bussi, M. G. B., De Villiers, M., Jones, K., Kortenkamp, U., Leung, A., \& Owens, K. (2016). Recent research on geometry education: An ICME-13 survey team report. ZDM Mathematics education, 48(5), 691-719.

Steele, M. D. (2013). Exploring the mathematical knowledge for teaching geometry and measurement through the design and use of rich assessment tasks. Journal of Mathematics Teacher Education, 16(4), 245-268.

Veloso, E. (1998). Geometria: Temas actuais. Lisboa: IIE.

Watson, A., \& Mason, J. (2007). Taken-as-shared: A review of common assumptions about mathematical tasks in teacher education. Journal of Mathematics Teacher Education, 10(4), 205-215.

Whiteley, W., Sinclair, N. \& Davis, B. (2015). What is spatial reasoning? In B. Davis \& Spatial Reasoning Study Group. Spatial reasoning in the early years: Principles, assertions, and speculations (pp. 3-14). New York, NY: Routledge. 